\title{
Management of Urban Stormwater Runoff in the Chesapeake Bay Watershed
}

Urban and suburban development is associated with elevated nutrients, sediment, and other pollutants in stormwater runoff, impacting the physical and environmental health of area streams and downstream water bodies such as the Chesapeake Bay. Stormwater management facilities, also known as Best Management Practices (BMPs), are increasingly being used in urban areas to replace functions, such as flood protection and water quality improvement, originally performed by wetlands and riparian areas (fig. 1).

Scientists from the U.S. Geological Survey (USGS) have partnered with local, academic, and other Federal agency scientists to better understand the effectiveness of different stormwater management systems with respect to Chesapeake Bay health. Management of stormwater runoff is necessary in urban areas to address flooding and water quality concerns. Improving our understanding of what stormwater management actions may be best suited for different types of developed areas could help protect the environmental health of downstream water bodies that ultimately receive runoff from urban landscapes.

\section{What are Best Management Practices?}

There are numerous land management actions that are considered to be BMPs. In general, a stormwater BMP is anything that is designed to lessen the negative impacts of land use on the environment. A physical, on-the-ground BMP does this by retaining, detaining, or allowing the infiltration of stormwater runoff into the ground water, thereby modifying the volume and

\section{Advancing the Understanding of Stormwater Management}

- Do enhanced stormwater management systems improve receiving stream water quality?

- What are the effects of alternate stormwater management programs?

- At a regional scale, how might location impact overall BMP effectiveness?

timing of runoff. In addition, a physical BMP may be designed to treat the stormwater runoff to improve water quality by retaining, removing, or at least reducing the pollution (including nutrients and sediment) that is generated by and washes off of urban and suburban areas during rainfall events. Different types of BMPs are appropriate for different site conditions; important considerations include soil type, slope of the surrounding land, depth of the water table, and surrounding land use. A few examples of physical, on-the-ground BMPs are shown in figure 2.

In addition to the physical, on-the-ground structures, BMPs also include land management actions, such as septic system checks and controls, street sweeping, and public education programs [for example, providing information about the proper disposal of used automobile oil (don't dump it in storm drains), and the appropriate use of fertilizers, herbicides, and pesticides].

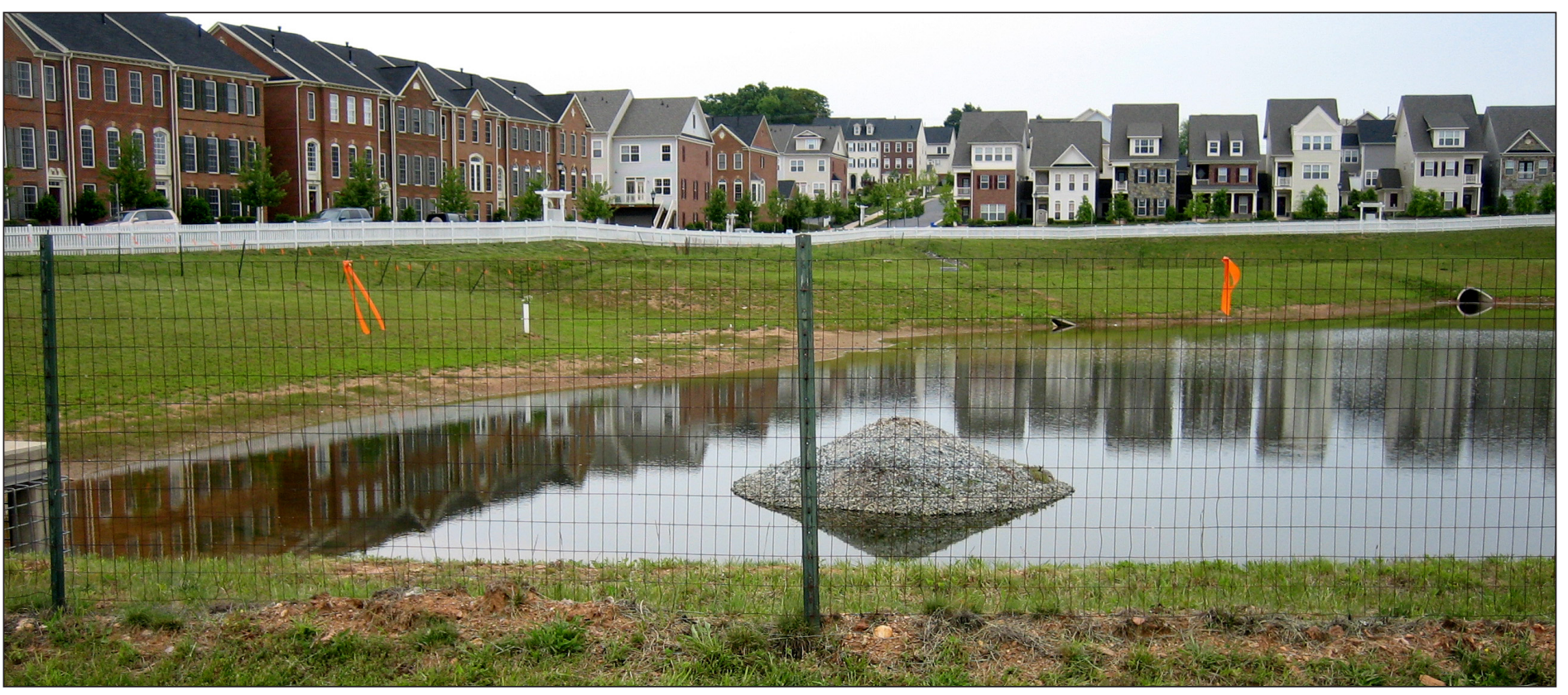

Figure 1. A stormwater BMP being used for sediment control in a developing watershed. 


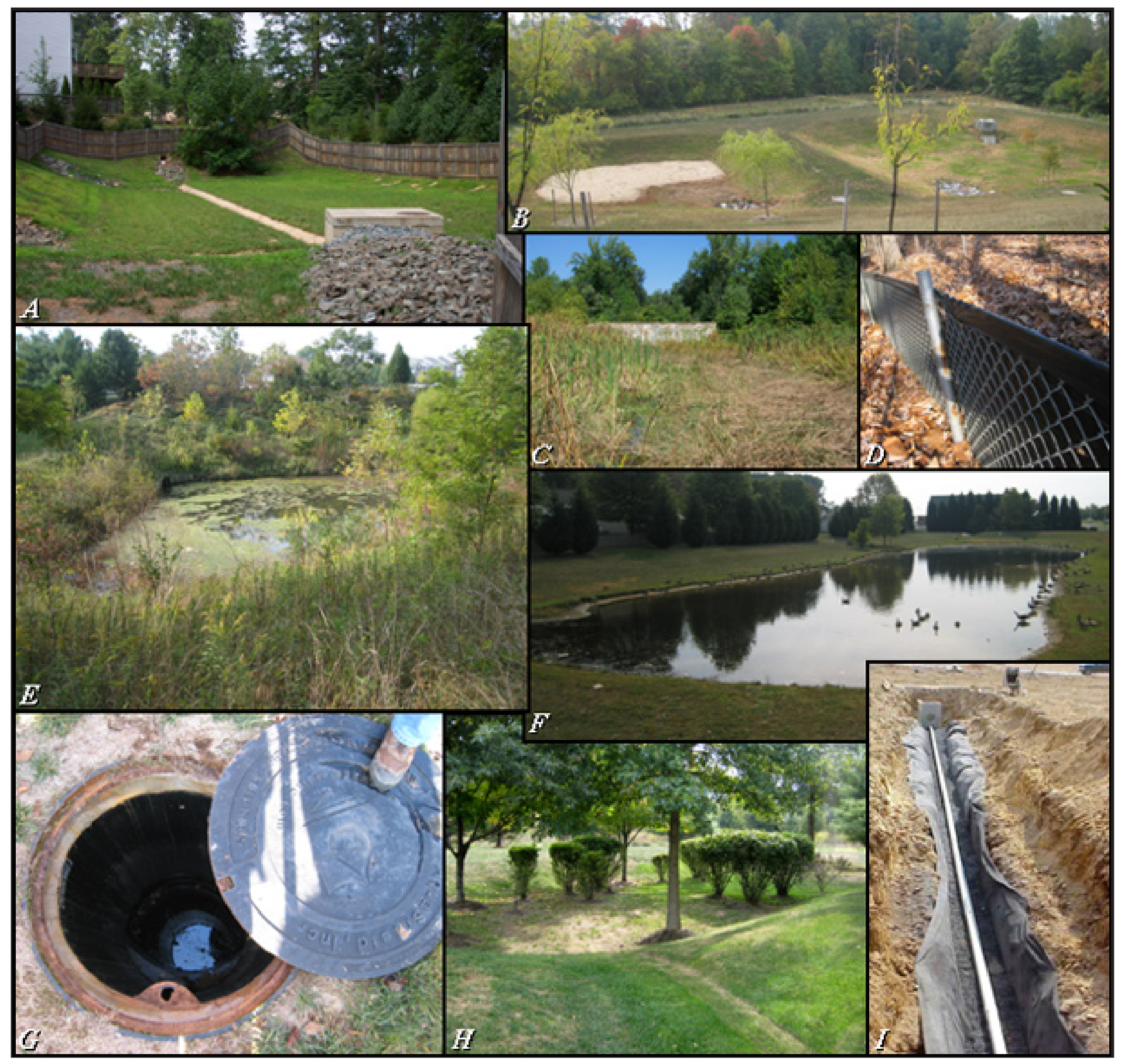

Figure 2. The many faces of stormwater Best Management Practices (BMPs): These are only a few examples of the many types of physical, on-the-ground BMPs designed for water quality protection. The photos show (A) detention basin, (B) surface sand filter in series with a detention basin, (C) enhanced detention basin, (D) super silt fence, (E, F) retention basin, (G) water quality manhole, (H) rain garden, and (I) the installation of an underground recharge trench. 


\section{The Clarksburg Special Protection Area}

One of our current focus areas is the Clarksburg Special Protection Area (CSPA) in Montgomery County, Md. The CSPA is undergoing rapid conversion from primarily agricultural and forested land to residential development, but has a goal of protecting the high quality streams in the area using BMP design. In cooperation with local, academic, and other Federal agencies, the USGS has built a database to map BMP spatial locations during (sediment control) and after (water quality management) development, relate BMP utilization patterns with area stream water quality, and provide a platform to help understand changing surface water pathways (fig. 3). We are interested in the effects of land use, landscape characteristics, and BMP type and spatial location on water quality - the removal or retention of nutrients, sediment, and other pollutants.

The CSPA BMP database includes:

- Orthophotography;

- Predevelopment and postdevelopment plans;

- Building footprints, roads, topography, and stormwater management infrastructure, conveyance, direction, and connectivity (pipes, swales, etc.);

- BMP characteristics (for example, location, type, drainage area, impervious cover, hydrologic connectivity, and water quality and quantity information); and

- Drainage area characteristics (for example, land cover, slope, and soils).

\section{Application and Future Research}

An understanding of the efficiency of BMPs, either already in use or planned as part of changing land use for residential development, is integral for meeting water quality goals in local as well as regional watersheds such as the Chesapeake Bay. USGS future research direction includes continuing the integra-

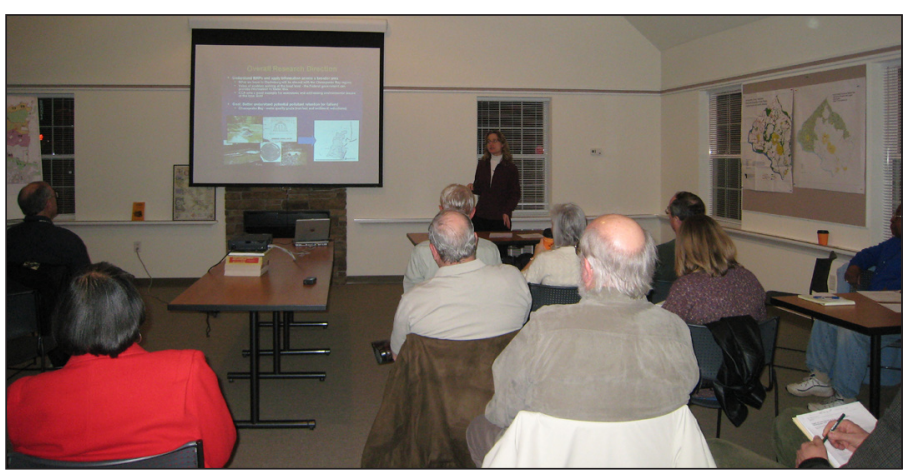

Figure 4. Scientists from USGS and Montgomery County explaining stormwater management and BMP use to concerned local property owners.

tion of BMP, land use, and environmental information in selected case study sites in the Chesapeake Bay watershed. These current and future analyses are designed to facilitate the understanding of the effects of urban land use on nutrient, sediment, and pollutant delivery to sensitive aquatic ecosystems and to better communicate the effectiveness of different stormwater management protocols to the public and land use decisionmakers (fig. 4).

\section{For more information, please contact:}

Dianna M. Hogan U.S. Geological Survey 521 National Center 12201 Sunrise Valley Drive

Reston, Virginia 20192 dhogan@usgs.gov

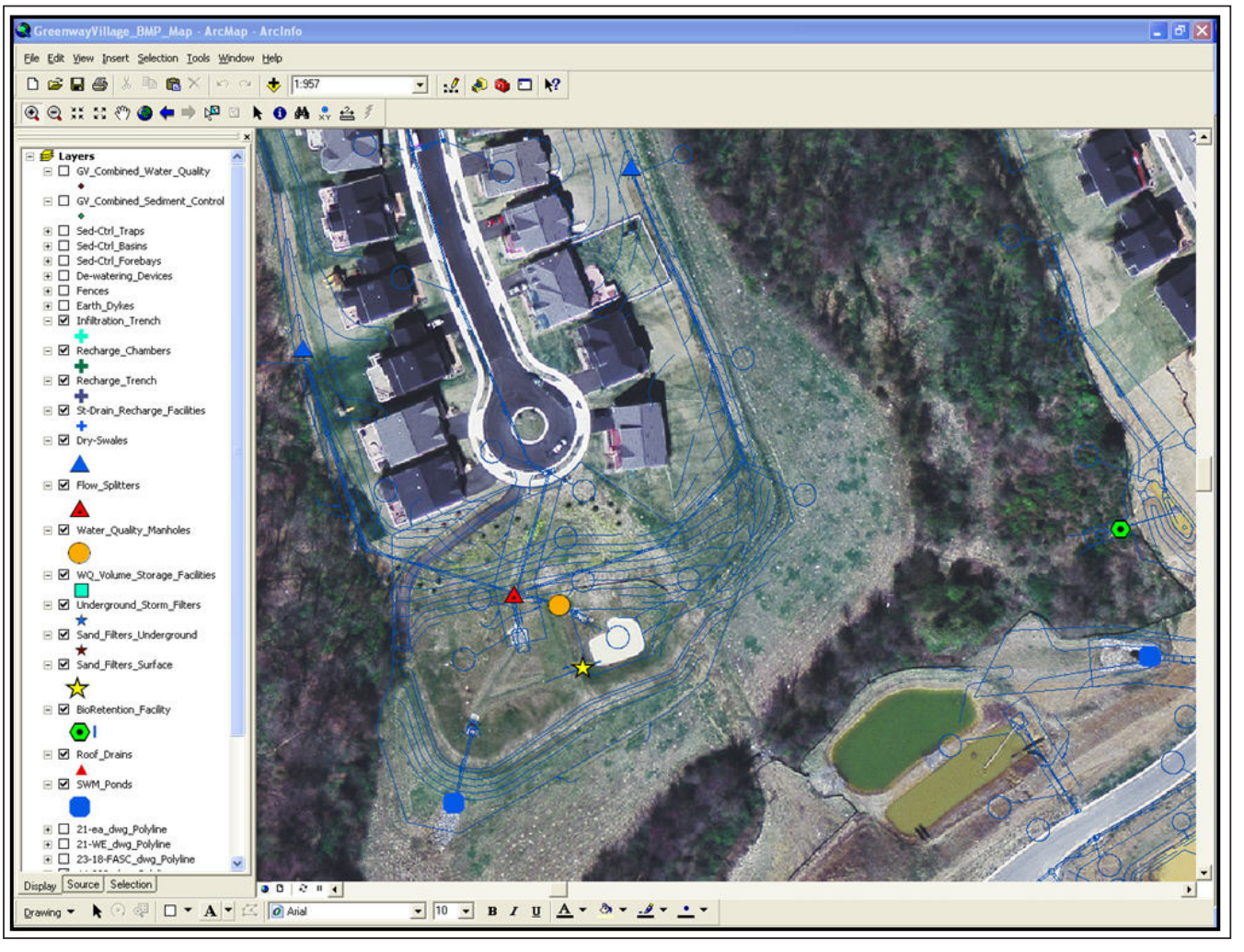

Figure 3. An image of orthophotography and GIS data for a section of the BMP database showing an example of the spatial configuration and connectivity of BMPs designed to address water quality, quantity, and timing issues. 